\title{
De Defensor de la Constitución a Principal Intérprete del Texto Constitucional y de los Derechos Fundamentales El Tribunal Constitucional en Perspectiva ¿Activista vs Garantista?
}

\author{
Nuria Belloso Martín
}

Catedrática de Filosofía del Derecho en la Universidad de Burgos (España). El presente trabajo se ha desarrollado en el marco del Proyecto de Investigación "Fundamentos teóricos del neoconstitucionalismo: un modelo jurídico para la sociedad global" (Código: DER2016-76392-P).nubello@ubu.es

El garantismo y el activismo gravitan como dos posibilidades enfrentadas sobre el Poder Judicial en general y, también, sobre la justicia constitucional. Se pondrá de relieve la evolución de la Corte Constitucional española (Tribunal Constitucional) que ha pasado de empezar siendo defensora de la Constitución, a tener como función primordial la interpretación del texto constitucional. Se citarán varias sentencias polémicas del Tribunal Constitucional español para poder entender la difícil labor que ha realizado en relación a delimitar las fronteras en el ejercicio de los derechos fundamentales. Se pondrá de manifiesto que el TC, además de sus luces, tiene también sus sombras y que convendría proceder a realizar algunas modificaciones, en aras de reforzar una de sus funciones como es la de ser garante de los derechos fundamentales.

Palabras-clave: Jurisprudencia constitucional. Garantismo. Activismo. Tribunal constitucional.

DE DEFENSOR DA CONSTITUIÇÃO A INTÉRPRETE PRINCIPAL DO TEXTO CONSTITUCIONAL E DOS DIREITOS FUNDAMENTAIS. O TRIBUNAL CONSTITUCIONAL EM PERSPECTIVA: ATIVISTA VS. GARANTISTA?

O garantismo e o ativismo gravitam como duas possibilidades enfrentadas sobre o poder Judiciário em geral e, também, sobre a Justiça constitucional. Salientar-se-á a evolução da Corte Constitucional espanhola (Tribunal Constitucional), que de iniciar sendo um instrumento em defesa da Constituição, ha mudado a ter como principal função a interpretação da Constituição. Serão citadas várias sentenças polêmicas do Tribunal Constitucional Espanhol para poder entender o difícil trabalho que se realizou em relação a estabelecer um limite de fronteiras no exercício dos direitos fundamentais. Explicar-se-á que o TC, ainda mais de ter luces, também tem sombras e que deveria se fazer um proceso de mudanças, para poder reforçar sua função de garantia dos direitos fundamentais. Palavras-chave: Jurisprudência constitucional. Garantismo. Ativismo. Tribunal constitucional.

1 Premisas: Garantismo y Activismo. 1.1 Garantismo. 1.2 Activismo. 2 La justicia constitucional como guardián de la constitución. El tribunal constitucional español. Sus principales funciones. 2.1 Las funciones del tribunal constitucional y su evolución. 2.2 ¿Qué derechos fundamentales se protegen principalmente por el tribunal constitucional español? 3 Sentencias del tribunal constitucional que cuestionan el garantismo y se aproximan al activismo. 3.1 Sentencias interpretativas. 3.2 Sentencias evolutivas. 4 Reflexiones finales. 


\section{Humanos e \\ Democracia}

\section{PREMISAS: GARANTISMO Y ACTIVISMO}

La configuración de un Estado de Derecho implica que se respeta la legalidad, legalidad que ha sido aprobada por el poder Legislativo, como representante de la voluntad popular. También implica el respeto al principio de separación de poderes, de manera que el Poder Judicial debe limitarse a aplicar e interpretar la ley pero no puede erogarse en legislador, a pesar de que esté tentado de hacerlo en su interpretación de los derechos fundamentales establecidos constitucionalmente. El garantismo sí puede ser un rasgo característico de un Estado de Derecho pero no el activismo judicial.

\subsection{Garantismo ${ }^{1}$}

La corriente del garantismo se proyecta sobre la filosofía jurídica y política e influye en la dogmática constitucional, penal y procesal. El aporte que el garantismo hace al constitucionalismo contemporáneo y a los neoconstitucionalismos - en definitiva al Estado - consiste en la actitud que promueve en la ciencia jurídica: defiende una concepción del Estado como instrumento al servicio de la protección de los derechos. El jurista no debe conformarse con ser un mero observador de las diferencias entre el ser y el deber ser sino que debe perseguir esos desajustes que detecte entre el horizonte de valores propuesto por la Constitución y el comportamiento de los operadores jurídicos -empezando por el propio legislador.

Además, el garantismo no se satisface con la mera denuncia, sino que requiere además la búsqueda de soluciones mediante el empleo de las garantías actualmente disponibles en el propio ordenamiento jurídico o, si estas son insuficientes, el diseño de nuevas garantías que permitan colmar la laguna causada por la existencia de una norma constitucional insuficientemente garantizada (NUNEZ LEIVA, 2010).

Las garantías son obligaciones o derechos correlativos a derechos subjetivos (intereses protegidos). Se identifican con expectativas (positivas o negativas). Los derechos fundamentales son expectativas de carácter universal (se atribuyen a todos) y consisten en expectativas negativas (límites al poder para los derechos derivados del principio de libertad) y expectativas positivas (obligaciones que corresponden a los poderes del Estado para los derechos derivados de la igualdad, como los derechos económicos, sociales y culturales.

El garantismo puede revestir diversas tipologías: garantismo propietario (patrimonial), penal, internacional (Declaraciones, Tratados). Sin garantías, el Derecho queda reducido a mero papel. Así, el derecho a la vida, si no se acompaña del Derecho Penal, quedaría reducido a mero papel.

\subsection{Activismo}

El activismo judicial no puede formar parte de un sistema democrático ya que va unido al riesgo del gobierno de los jueces. Es lo que se ha denominado como objeción contramayoritaria del Poder Judicial (BELLOSO MARTín, 2017). Los defensores de esta perspectiva afirman, básicamente, que el Poder Judicial, al no ser elegido por el pueblo - más que de una

\footnotetext{
${ }^{1}$ La rúbrica Garantismo se halla vinculada de manera inseparable a la figura de Luigi Ferrajoli. La ha expuesto en sus obras Derecho y Razón. Teoría del garantismo penal y en Principia Juris, Teoría del derecho y de la democracia, entre otras.
} 
forma muy mediata- no puede, al ejercer el control de constitucionalidad, ser el censor de los otros dos poderes estatales, los cuales sí cuentan con el aval de los votos, es decir, con legitimidad democrática propia. Es decir, los jueces como garantes de las decisiones tomadas en el momento constitucional han sido vistos con recelo porque en el fondo, eso podría terminar en el gobierno de la judicatura. Es el temor a que se produzca una mutación del paradigma de la toma de decisiones, "pasándose de uno "democrático" a otro "elitista", el cual se corporiza en una minoría (los jueces) que toman decisiones que solamente corresponderían al pueblo y a sus representantes erigidos por sufragio".

Para entender adecuadamente el activismo judicial, habría que partir de una distinción, entre la autorrestricción judicial y su contrario, el activismo judicial.

El punto de partida de la autorrestricción judicial es el principio de división de poderes y una concepción de la democracia formalista. Sustenta que los jueces carecen de legitimidad democrática y que son los menos autorizados para controlar la legalidad y la constitucionalidad de las normas.

Por el contrario, el activismo judicial y el decisionismo judicial sustentan que, sin contrapesos democráticos, se posibilitaría la salvaguardia de los derechos fundamentales y especialmente, derechos de las minorías - consagrados en la Constitución. Su actividad se podría calificar de prácticas cercanas al "populismo judicial". Se sustenta en que es la justa intervención del aparato de justicia como equilibrador ante la indolencia y paquidermia de otros órganos de poder.

En esta contraposición entre activismo y decisionismo, hay que tener presente que el Tribunal Constitucional, en cuanto defensor de los derechos fundamentales -ya se indicará que no se creó como instancia protectora de derechos humanos sino como garante de la Carta Magna - no se configura como la última instancia. El Tribunal Europeo de Derechos Humanos se ha convertido en un garante de esos derechos fundamentales.

Conviene recordar el doble sistema de protección de los derechos en Europa según el cual, en el ámbito regional europeo coexisten dos Tribunales: el Tribunal Europeo de Derechos Humanos (TEDH), ${ }^{2}$ también conocido como Tribunal de Estrasburgo, y el Tribunal de Justicia de la Unión Europea (TJUE) también conocido como Tribunal de Luxemburgo. ${ }^{3}$ El Tribunal Europeo de Derechos Humanos es el Tribunal destinado a enjuiciar, bajo determinadas circunstancias, las posibles violaciones de los derechos reconocidos en el Convenio Europeo de Protección de los Derechos Humanos y de las Libertades Fundamentales (CEDH) y en sus

\footnotetext{
${ }^{2}$ El Convenio Europeo de Derechos Humanos fue aprobado mediante el Convenio de Roma de 1950. "HUDOC": hudovs.echr. coe.int

${ }^{3}$ https://curia.europa.eu/jcms/jcms/j_6/es/

El lema de la Unión Europea es "Unidos en la diversidad", lo que permite entender que uno de sus rasgos característicos sea precisamente el de la unidad en la diversidad. Es decir, se basa en un proceso de apertura hacia el otro y que trasciende el mero ámbito económico. El Derecho comparado es connatural al Derecho de la Unión porque sirve de instrumento para alcanzar esa comparación de la unidad en la diversidad. La tensión dinámica entre la unidad y la multiplicidad es clave en el derecho de la UE, tal y como ha subrayado Beck (2005).
} 


\section{Democracia}

Humanos e

Protocolos por parte de los Estados parte de dicho Convenio. ${ }^{4}$ Después de la entrada en vigor del Tratado de Lisboa, la relación entre el TEDH y el TJUE ha ido adquiriendo mayor dinamismo en relación a la recíproca confianza y al diálogo (MARTINICO, 2018, p. 27). ${ }^{5}$ Ello es imprescindible para evitar, por ejemplo, que un Estado Parte en la CEDH y al mismo tiempo miembro de la UE, se halle frente a dos interpretaciones divergentes, una procedente del Tribunal de Luxemburgo y la otra del Tribunal de Estrasburgo. ${ }^{6}$

En la experiencia española, puede señalarse que ha primado el garantismo y no el activismo judicial. Por ejemplo, se tiende sistemáticamente a no dar razón a los ciudadanos como resultado de los conflictos con Bancos, con compañías de seguros o con empleadores (desalojos, acciones preferidas compradas a los Bancos, cláusulas-suelo). Incluso esto ha supuesto que la Jurisprudencia del Tribunal de Justicia de la Unión Europeo (TJUE), en algunas de sus últimas sentencias, haya emendado sentencias de tribunales españoles, como el Tribunal Supremo.7

\footnotetext{
${ }^{4}$ Además de los dos tribunales citados, a nivel de la unión Europea hay otro órgano defensor de los derechos humanos como es el Defensor del Pueblo europeo. El Defensor del Pueblo es un órgano independiente e imparcial encargado de garantizar que las agencias e instituciones de la UE se atienen a la obligación de rendir cuentas, así como de promover la buena administración. El Defensor del Pueblo ayuda a las personas, empresas y organizaciones que se enfrentan a problemas con la administración de la UE investigando las reclamaciones de mala administración relativas a las instituciones y organismos de la UE, pero también examinando de forma proactiva cuestiones sistémicas más amplias. https://www.ombudsman.europa.eu/es/home

${ }^{5}$ El Tratado de Lisboa ha introducido nuevos elementos interesantes en relación a la inclusión de una serie de disposiciones relativas a los materiales constitucionales nacionales. A modo de ejemplo se puede mencionar la incorporación de cláusulas que se refieren a "las legislaciones y prácticas nacionales" en el texto de la Carta de Derechos Fundamentales de la UE (derecho a contraer matrimonio y fundar una familia, libertad de pensamiento, de conciencia y de religión; derecho a la educación; derecho a la información y consulta de los trabajadores en la empresa; derecho de negociación y de acción colectiva; protección a la salud, etc.). Estas tradiciones nacionales pueden llegar a considerarse como una especie de doctrina de margen de apreciación difundida a nivel de la UE Entre esas cláusulas citadas hay que destacar la cláusula 4.2 TUE.

${ }^{6}$ El día 1 de agosto de 2018 entró en vigor del Protocolo núm. 16 que introduce la posibilidad de que los órganos jurisdiccionales nacionales de mayor rango puedan solicitar al TEDH opiniones consultivas relativas a la interpretación y aplicación del $\mathrm{CEDH}$, con el objeto de facilitar la protección de derechos a nivel nacional, lo que eleva las posibilidades del diálogo entre jurisdicción interna y TEDH.

7 Sentencia del Tribunal de Justicia UE (Gran Sala) de 21 de diciembre de 2016.

https://ep00.epimg.net/.../26aea35b8c66e78f3169264b9f90ecbe...
}

Esta sentencia versa sobre la retroactividad de las devoluciones de las cantidades cobradas indebidamente por los bancos en aplicación de las cláusulas suelo de las hipotecas. La sentencia establece que, en contra de lo establecido por el Tribunal Supremo de España en el sentido de que la retroactividad de las devoluciones sólo debía aplicarse a partir de mayo de 2013 que el Derecho de la Unión se opone a una jurisprudencia nacional en virtud de la cual los efectos restitutorios vinculados a la nulidad de una cláusula abusiva se limitan a las cantidades indebidamente pagadas con posterioridad al pronunciamiento de la resolución judicial mediante la que se declare el carácter abusivo de la cláusula. Esto supone que los consumidores afectados por las cláusulas suelo podrán exigir la devolución de todo el dinero que se les haya cobrado de más desde el momento de la suscripción de su préstamo.

Otro ejemplo es la Sentencia del Tribunal de Justicia UE (Sala Tercera), de 8 de mayo de 2019. Este caso se planteó como un Procedimiento prejudicial relativo a la igualdad de trato entre hombres y mujeres en materia de seguridad social (Directiva 79/7/CEE, Artículo 4: Prohibición de toda discriminación por razón de sexo) así como en relación a Discriminación indirecta, Trabajo a tiempo parcial y Cálculo de la pensión de jubilación». http://curia.europa.eu/juris/document/document. jsf?text=\&docid=213852\&pagelndex=0\&doclang=ES\&mode=Ist \&dir=\&occ=first\&part=1\&cid $=7555428$

España tiene que revisar la normativa del cálculo de la pensión para los trabajadores a tiempo parcial, ya que podría ser discriminatorio contra las mujeres. El TJUE parte de la base de que el tiempo parcial afecta principalmente a las mujeres (en torno al $75 \%$ del total). Como esta modalidad contractual tiene un coeficiente reductor para el cálculo de la vida laboral, entonces significaría que afectaría fundamentalmente a las mujeres, por lo que sería contraria al derecho comunitario por discriminación. El TJUE no entra a valorar si realmente existe discriminación, y esa interpretación se la deja a la justicia española. Pero sí es contundente en su sentencia: si existe discriminación, entonces es contraria al derecho. 
Pero es especialmente relevante los derechos humanos protegidos por la jurisprudencia del $\mathrm{TEDH}^{8}$ tales como: derecho europeo de acceso a la justicia; derechos del niño; protección de datos; asilo, fronteras e inmigración; contra la discriminación. ${ }^{9}$

\section{LA JUSTICIA CONSTITUCIONAL COMO GUARDIÁN DE LA CONSTITUCIÓN. EL TRIBUNAL CONSTITUCIONAL ESPAÑOL. SUS PRINCIPALES FUNCIONES}

Establecido por el Título IX de la Constitución Española de 1978 (en adelante CE), el Tribunal Constitucional (TC) es el intérprete supremo de la Constitución. Único en su orden y con jurisdicción en todo el territorio nacional, ejerce las competencias definidas en el art. 161 CE. Al Tribunal se le ha encomendado, en defensa de la Constitución, el control de los actos y resoluciones de los tres poderes del Estado. EI TC procura no pronunciarse sobre la constitucionalidad de los preceptos legales, limitándose a hacerlo sobre su inconstitucionalidad o, en su caso, no constitucionalidad (OLLERO TASSARA, 2018, p. 97). El Tribunal Constitucional es independiente de los demás órganos constitucionales y está sometido sólo a la Constitución y a su Ley Orgánica $2 / 1979$, de 3 de octubre. ${ }^{10}$

\subsection{Las funciones del Tribunal Constitucional y su evolución}

El recurso de amparo ante el TC - podría considerarse como uno de las manifestaciones de una justicia constitucional garantista - es una de las garantías que la Carta Magna establece para tutelar algunos de los derechos y libertades de los ciudadanos. ${ }^{11}$

8 https://www.mjusticia.gob.es/cs/Satellite/Portal/es/areas-tematicas/area-internacional/tribunal-europeo-derechos/jurisprudencia-tedh/articulo-derecho-vida\#Se_1288807922455_1

9 https://www.mjusticia.gob.es/cs/Satellite/Portal/es/areas-tematicas/area-internacional/tribunal-europeo-derechos/manuales-fichas-tematicas

${ }^{10}$ Conforme a la CE y a su Ley Orgánica, el Tribunal Constitucional es competente para conocer:

a. Del recurso de inconstitucionalidad contra leyes, disposiciones normativas o actos con fuerza de ley.

b. De la cuestión de inconstitucionalidad sobre normas con rango de ley.

c. Del recurso de amparo por violación de los derechos y libertades referidos en el art. 53.2 CE.

d. De los conflictos de competencia entre el Estado y las Comunidades Autónomas, o de éstas entre sí.

e. De los conflictos entre los órganos constitucionales del Estado (Congreso, Senado, Gobierno y Consejo General del

Poder Judicial).

f. De la declaración sobre la constitucionalidad de los Tratados internacionales.

g. De la impugnación por el Estado de las disposiciones y resoluciones adoptadas por los órganos de las Comunidades

Autónomas.

h. De los conflictos en defensa de la autonomía local.

De las demás materias que le atribuyan las Leyes Orgánicas (art. 161.1.d CE).

${ }^{11}$ Artículo 53.2: Cualquier ciudadano podrá recabar la tutela de las libertades y derechos reconocidos en el artículo 14 y la Sección primera del Capítulo segundo ante los Tribunales ordinarios por un procedimiento basado en los principios de preferencia y sumariedad y, en su caso, a través del recurso de amparo ante el Tribunal Constitucional. Este último recurso será aplicable a la objeción de conciencia reconocida en el artículo 30.

El recurso de amparo es una de las principales competencias atribuidas por la Constitución al Tribunal Constitucional, siendo el objeto de este proceso la protección frente a las vulneraciones de los derechos y libertades reconocidos en los artículos 14 a 29 y 30.2 de la Constitución originadas por disposiciones, actos jurídicos, omisiones o simples vías de hecho de los poderes públicos del Estado, las Comunidades Autónomas y demás entes públicos de carácter territorial, corporativo o institucional, así como de sus funcionarios o agentes. La única pretensión que puede hacerse valer a través del recurso de amparo es la del restablecimiento o preservación de los derechos o libertades por razón de los cuales se promueve el recurso.

La Ley Orgánica del Tribunal Constitucional distingue tres modalidades de recurso de amparo en razón del origen del acto del poder público al que se le imputa la vulneración de los derechos fundamentales: a) recurso de amparo contra decisiones parlamentarias (art. 42); b) recurso de amparo contra decisiones gubernativas y administrativas (art. 43); c) recurso de amparo contra decisiones judiciales (art. 44). 


\section{Humanos e}

Democracia

La ley Orgánica 6/2007, de 24 de mayo, dio lugar a lo que se ha venido a denominar como "nuevo recurso de amparo". Tal reforma se proponía una objetivación del recurso de amparo:

Descartando su arraigada conversión subjetiva en tercera instancia procesal. Como consecuencia, el centro de gravedad del decisivo trámite de admisión se trasladaba a la previa constatación de tasados motivos de inadmisión, incluida la no apreciable vulneración de un subjetivo derecho fundamental, a la argumentación justificadora de una objetiva especial trascendencia constitucional (OLLERO TASSARA, 2018, p. 100).

Anualmente, se presenta un alto volumen de recursos de amparo ante el TC pero, al aplicarse el nuevo filtro, un elevado porcentaje es inadmitido. El profesor Ollero facilita algunos datos: En el quinquenio 2011-2015 se han presentado más de 7.000 recursos - revelando una desproporción con el resto de los asuntos ingresados en el TC - mientras que las sentencias que se dictan sobre los mismos, anualmente, $-y$, evidentemente, no todas estimatorias - no llegan a cien. Posiblemente, el requisito de la "derecho" conlleva que, para redactar una demanda de amparo, hay que poseer una cualificación profesional que implica el dominio de la doctrina y jurisprudencia -tanto del propio TC como del Tribunal Europeo de Derechos Humanos - sobre los derechos fundamentales susceptibles de amparo (ARAGÓN REYES, 2012, p. 9).

En un $37 \%$ de los casos la inexistencia o insuficiencia de la justificación de el derecho llevó a la inadmisión, mientras que en un porcentaje similar, la causa fue la previsible ausencia de la vulneración; en otro $15 \%$, la cusa fue por motivos procesales - tales como no haber agotado la previa vía judicial o la extemporaneidad.

Hay que destacar la evolución del Tribunal Constitucional: de empezar siendo defensor de la Constitución, a tener como función primordial la interpretación del texto constitucional.

El Tribunal Constitucional no actúa aquí como un defensor de la Constitución frente a sus enemigos - que han sido históricamente los legisladores - sino más bien como un garante de su eficacia diaria en las relaciones con poderes públicos y con particulares.

La interpretación de la Constitución, que trata de determinar su significado y de armonizar sistemáticamente sus preceptos, cuando no la auténtica creación del orden constitucional, y la interpretación de la ley de conformidad con la Constitución, que establece la orientación constitucional de todo el ordenamiento y dota de criterios constitucionales a la actuación del resto de los poderes públicos son funciones que se imponen a la ya tradicional de defensa de la Constitución.

a) La prevalencia de la función interpretativa sobre la de defensa de la Constitución se concreta también en la importancia que cobra dentro de la actividad del Tribunal su labor protectora de los derechos fundamentales frente a las vulneraciones de los poderes públicos y, en menor medida, de los particulares. Si bien es cierto que una ley contraria a la Constitución es un atentado grave a ésta - ya que la Ley debe ser aplicada por Administración, jueces y ciudadanos -, la realidad es que la lesión más habitual de los derechos fundamentales procede de poderes públicos distintos al legislador. Estas lesiones de los derechos fundamen- 
tales por la Administración, por los jueces o por particulares no representan una amenaza global a la Constitución ni al orden democrático, sino un ataque a la normatividad de la misma y a su eficacia práctica en la sociedad.

A través de la resolución de los recursos de amparo, el Tribunal Constitucional reconoce el derecho fundamental y restablece al recurrente en la integridad del mismo, declarando nulos los actos que hayan originado la lesión. A la vez, el procedimiento de amparo constitucional brinda al Tribunal una oportunidad para establecer criterios de interpretación de los derechos fundamentales.

b) La resolución de conflictos territoriales (qué competencias corresponden a cada Comunidad Autónoma cuando están transferidas - sanidad, educación - Estatutos de Autonomía, autogobierno de Cataluña) han ido incrementando en número de presentación de recursos de inconstitucionalidad (JIMENO BULNES, 2018).

Tanto la resolución de conflictos territoriales como la ya mencionada protección de los derechos fundamentales no tienen una vinculación clara con la defensa de la Constitución sino más bien con el establecimiento de principios de interpretación constitucional. Es decir, en estos procedimientos no se da tanto una defensa de la Constitución frente a sus enemigos sino una defensa de su contenido. La función constitucional de resolución de conflictos territoriales es la más destacada aportación del Alto Tribunal al desarrollo constitucional en nuestro país, debido tanto a la imprecisión del texto constitucional en relación al reparto territorial del poder, como a la conflictividad que esto ha originado.

c) En cambio, la dimensión de defensa de la Constitución prevalece en otros procedimientos específicos como la resolución de conflictos entre órganos constitucionales o en procesos electorales, el pronunciamiento sobre la admisibilidad de referendos, la decisión acerca de la constitucionalidad de los partidos políticos, etc.

\section{$2.2 ¿ Q u e ́$ derechos fundamentales se protegen principalmente por el Tribunal Constitucional español?}

Son varios los derechos fundamentales que han sido objeto de un mayor número de recursos de amparo. Destacamos algunos, citando algunas de las sentencias que han contribuido a clarificar cómo deben interpretarse esos derechos fundamentales:

a. El derecho a la libertad personal y al procedimiento de habeas corpus

- La STC 341/1993, de 18 de noviembre - Caso Ley de Seguridad Ciudadana -, que corrige la doctrina anterior, afirmando la legitimidad constitucional de la retención policial para la práctica de la diligencia de identificación y acompañamiento.

- La STC 86/1996, de 21 de mayo - Caso García Melani - recalca que el tiempo máximo de detención preventiva es el estrictamente necesario para el esclarecimiento de los hechos, sin que el plazo de setenta y dos horas pueda ser una opción libre de la autoridad gubernativa.

b. La libertad de expresión ha sido principalmente expuesta en:

- La STC 105/1990, de 6 de junio - Caso José María García - recuerda que la libertad de expresión e información no implica ningún derecho al insulto; 


\section{Humanos e}

Democracia

- Las SSTC 171 y 172/1990, de 12 de noviembre - casos Comandante Patino I y II - reflejan la necesaria ponderación judicial del equilibrio entre libertad de información y derecho al honor, teniendo en cuenta tanto el objeto de la información como la forma de ésta.

- La STC 176/2013, 21 de octubre de 2013. Recurso de amparo 1783-2010. Promovido por don Francisco Álvarez-Cascos Fernández y doña María Porto Sánchez en relación con la Sentencia de la Sala de lo Civil del Tribunal Supremo que desestimó su demanda por las imágenes y comentarios difundidos en el programa televisivo "Crónicas Marcianas". El fallo del TC otorgar el amparo solicitado por don Francisco Álvarez-Cascos Fernández y doña María Porto Sánchez y, en consecuencia, reconoce los derechos fundamentales de los demandantes a la intimidad y a la propia imagen (art. 18.1 CE).

- $\quad$ STC del pleno 177/2015, de 22 de julio. Libertad de expresión vs. injurias al Rey. Los acusados, que acudieron disfrazados para impedir que los identificaran, después de una concentración en contra de la Corona, tomaron en público la fotografía del Rey - mostrándola al revés - le dan fuego, consumiendo dicho "fuego purificador" la fotografía de la discordia y que fundamenta la imposición de la pena.

Extensamente se ha pronunciado el TC, elaborando una consolidada doctrina constitucional que reconociendo la libertad de expresión, que si bien es un derecho fundamental, éste no es un derecho absoluto, y en determinados casos debe ceder ante otros derechos en un difícil juego de equilibrios que debe resolver el Tribunal en su función de establecer el canon de protección, estableciendo la fina línea que constituyen los límites del derecho. El límite de la libertad de expresión, como regla general, se establece en lo que reconoce como "discurso del odio", y/o con el uso de la violencia. La Sentencia resuelve en contra de los intereses de la parte recurrente -aquéllos que habían procedido a la quema de la foto del Rey - fundamentando que éstos habían sobrepasado el límite relativo al "discurso al odio", considerando que la acción que antes he descrito va más allá de una mera manifestación política, proyectando con la quema, como elemento destructor, y por tanto cargado de negatividad, al odio y/o a la violencia de quienes se encontraban en el lugar de los hechos.

c. El derecho a la tutela judicial efectiva

- La STC 199/1987, de 16 de diciembre - Caso Ley Antiterrorista - analiza el derecho al juez ordinario predeterminado por la ley en relación a la existencia de la Audiencia Nacional.

- La STC 227/1994, de 17 de diciembre - Caso Spie - aborda la vulneración del derecho a la tutela judicial efectiva por deficiencias en la comunicación de la Administración de Justicia con las partes durante el proceso.

- La STC 30/2014, 24 de Febrero de 2014. Notificaciones. Domicilio desconocido. Se ha vulnerado el derecho a la tutela judicial efectiva sin indefensión del demandante, por la falta de diligencia del órgano judicial en su obligación de agotar los medios de averiguación del domicilio real para obtener una notificación personal y efectiva. 
d. El principio de igualdad

- La clarificación del principio de igualdad en la aplicación de la ley ha dado lugar a numerosas sentencias.

- La STC 128/1987, de 16 de julio - Caso Guarderías - analiza la constitucionalidad del trato especialmente beneficioso al sexo femenino, distinguiéndolo de aquel otro trato favorable que parte de una concepción secundaria o de debilidad de la mujer.

- La STC 42/1993, de 8 de febrero - Caso Fernández - contiene la doctrina constitucional sobre la igualdad en la aplicación de la ley, diferenciando en las resoluciones judiciales contradictorias lo que es una evolución legítima del criterio del juzgador de lo que es una divergencia derivada de una arbitrariedad del órgano judicial.

e. El derecho a la intimidad

- La STC 39/2016, 3 de marzo de 2016. La empresa en la que prestaba sus servicios la recurrente en amparo instaló una cámara de videovigilancia, sin notificarlo expresamente a los trabajadores, aunque en un lugar visible del establecimiento se colocó un distintivo informativo. En virtud de las imágenes captadas, se constató que la demandante en amparo se había apropiado de efectivo de la tienda, razón por la que fue despedida. Frente a ello, la recurrente solicitó la declaración de nulidad del despido, ya que consideró que la empresa había incumplido la normativa referida a la instalación de mecanismos de grabación. Se desestima el recurso. En aplicación de la doctrina sentada en la STC 292/2000, la Sentencia declara que fueron respetadas las reglas relativas al tratamiento de datos personales.

- La STC 170/2013, 7 de octubre de 2013. Recurso de amparo con respecto a la Sentencia dictada por la Sala de lo Social del Tribunal Superior de Justicia de Madrid en proceso por despido. El Tribunal considera que la conducta empresarial de fiscalización ha sido conforme a las exigencias del principio de proporcionalidad. Se desestima el recurso de amparo.

f. El Derecho al honor

- La STC 214/1991, de 11 de noviembre, más conocida como el "caso Violeta Friedman" dio respuesta al recurso de amparo núm. 101/90, promovido por doña Violeta Friedman. La Sra. Friedman, judía, fue internada durante la Segunda Guerra Mundial en un campo de concentración, junto a su familia. Esta sobrevivió al mismo, junto con su hermana, pero el resto de su familia no superó el genocidio nazi. En relación a este caso, son los comentarios de un ex general nazi en una revista, que niega el genocidio del pueblo judío, los que Violeta Friedman considera que lesionan su derecho al honor.

- Y es que, aunque los comentarios no iban dirigidos a la propia Violeta Friedman, el Tribunal Constitucional aprecia el interés legítimo de la misma para reaccionar ante los mismos (los jueces anteriormente no le habían reconocido el derecho a acudir a los tribunales, sí el Tribunal Constitucional). 


\section{Humanos e \\ Democracia}

g. Libertad religiosa vs Derecho a la vida

- Es destacable la Sentencia TC 154/2002, de 18 de julio. El origen de este caso fue la caída en 1994 de Marcos Alegre Vallés, de 13 años, desde la bicicleta en la que paseaba por la población de Ballobar (Huesca). Como consecuencia de la caída, el menor se lesionó en una pierna y tres días después sangró por la nariz y se puso pálido, por lo que sus padres le sometieron a asistencia sanitaria. Planteada la necesidad de una transfusión de sangre, los padres invocaron la condición familiar de ser testigos de Jehová, se opusieron a ella y solicitaron el alta para su hijo, a pesar de que los sanitarios aseguraron que no existían tratamientos alternativos. El centro hospitalario no accedió a dar el alta, dado el peligro para la vida del menor, y solicitó del juzgado de guardia autorización para practicar la transfusión, que fue concedida.

- Acatada por los padres del niño la decisión judicial, el menor, sin intervención alguna de los padres, la rechazó - según los hechos declarados probados por los órganos judiciales competentes - con auténtico terror, reaccionando agitada y violentamente en un estado de gran excitación, que los médicos estimaron contraproducente, pues podía precipitar una hemorragia cerebral, por lo que desistieron de realizar la transfusión.

- El pleno del Tribunal Constitucional ha amparado el derecho fundamental a la libertad religiosa de una pareja de testigos de Jehová cuyo hijo, de 13 años, falleció a raíz de la negativa del menor a recibir una transfusión de sangre. Los padres habían sido condenados a dos años y medio de cárcel por homicidio por la Sala Penal del Tribunal Supremo, que consideró que, como garantes del menor, debieron convencerle para recibir sangre. En cambio, el Tribunal Constitucional, anula la condena desde la apreciación de que el menor ejerció su derecho a la libertad religiosa, no estima exigible que los padres se opusieran a tal ejercicio, en contradicción también con sus propias creencias.

\section{SENTENCIAS DEL TRIBUNAL CONSTITUCIONAL QUE CUESTIONAN EL GARANTISMO Y SE APROXIMAN AL ACTIVISMO}

Hay algunas tipologías de sentencia derivadas de la justicia constitucional (por tanto, del TC) que van más allá de resolver sobre la demanda planteada. Entre estas sentencias cabe destacar las denominadas sentencias interpretativas y sentencias evolutivas (FERNÁNDEZ SEGADO, 2011).

\subsection{Sentencias interpretativas}

En los últimos años algunas de las decisiones más delicadas se han resuelto no a través de la solución más traumática de la declaración de inconstitucionalidad, sino mediante decisiones interpretativas, que, en ocasiones, han provocado cambios estructurales en el sistema sin gran repercusión pública.

Son aquellas sentencias que presentan alguna de las interpretaciones posibles como conforme con la Constitución. Las sentencias interpretativas responden a la exigencia práctica de evitar vacíos (vuoti) en el ordenamiento. Es una solución polémica porque cabe el riesgo 
de que se acabe atribuyendo tal condición a una interpretación que -si interpreta en demasía - debería ser considerada contra legem. Las sentencias interpretativas pueden ser tanto desestimatorias como estimatorias.

Sin embargo, para el sistema democrático el uso espurio, por parte del Tribunal Constitucional, acabar produciendo distorsiones. Así, las denominadas "sentencias de inconstitucionalidad sin nulidad": sentencias desestimatorias que señalan la interpretación de los preceptos impugnados que es conforme con la Constitución.

Se advierte cierta tendencia psicológica de los jueces constitucionales por las sentencias interpretativas cuando se refieren a los temas políticamente más controvertidos (Zagrebelsky). El problema es que al cobijo de este tipo de resoluciones nos encontremos con actuaciones en las que el intérprete supremo se coloca en el papel del que toma decisiones políticas o, más allá, pasa a reescribir los preceptos constitucionales de acuerdo con las convicciones políticas y morales de sus magistrados, olvidando que es un tribunal (bien sea de manera más encubierta -apelando al garantismo - o sin tanto disimulo).

Como ejemplo de lo expuesto, cabe destacar dos de las decisiones más polémicas del Tribunal Constitucional:

a. La sentencia sobre Bildu (sentencia 43/2009, de 12 de febrero): Los dos partidos legales de la coalición electoral, Eusko Alkartasuna (EA) y Alternatiba (una escisión de Ezker Batua), que habían quedado fuera de la cita electoral, pudieron concurrir en Bildu (partido afín al grupo terrorista ETA) junto a los independientes que el Supremo identificó con la ilegalizada Batasuna.

b. La sentencia sobre el Estatuto de Cataluña (STC Pleno. Sentencia 31/2010, de 28 de junio de 2010): En 2006 el Partido Popular impugnó 114 artículos del Estatuto de Cataluña. Recurso de inconstitucionalidad 8045-2006. Interpuesto por noventa y nueve Diputados del Grupo Parlamentario Popular del Congreso en relación con diversos preceptos de la Ley Orgánica 6/2006, de 19 de julio, de reforma del Estatuto de Autonomía de Cataluña.

El Constitucional aprobó un recorte moderado que permitía aplicar el Estatuto de Cataluña. El alto tribunal alcanzó el fallo con una votación por bloques en la que los jueces conservadores lograron que el término "nación" no tuviese eficacia jurídica. Un fallo histórico, por su simbología política.

c. Normas de Derechos fundamentales como normas de principio.

En general las normas de derechos fundamentales responden al modelo de las normas de principio, pues se presentan en la mayoría de los casos como enunciados que no establecen las reglas jurídicas precisas atinentes a la conducta o conductas protegidas y a los instrumentos de su protección. Si la interpretación constitucional implica una tarea en gran medida creadora, el margen de creatividad se incrementa cuando el enunciado constitucional responde a una norma de principio.

Decidir si una persona que está procesada puede ser candidata en un concreto proceso electoral o si un partido puede ser ilegalizado no por lo que hace sino por lo que omite, depende de cómo se interprete el papel que la Constitución reserva a la participación política y a los partidos en ese sistema democrático y en ello está en juego el propio principio democráti- 


\section{Humanos e}

Democracia

co sobre el que descansa el Estado. Por eso, es preocupante que a través de decisiones interpretativas del TC se acuda a una vía espuria para realizar cambios estructurales en el sistema constitucional y para neutralizar conflictos políticos.

Por ejemplo, la STC 48/2003 sobre la L. 0. 6/2002, de partidos políticos. Algunos de los argumentos que el TC utilizó para concluir que los preceptos impugnados no eran contrarios a la Norma Fundamental.

El Tribunal Constitucional, a través de la técnica de la interpretación conforme a la Constitución, ha actuado en muchos casos como un auténtico legislador positivo. Como conocemos, un summum ius puede traducirse a veces en una summa iniuria. En ocasiones, los Tribunales han creado técnicas decisorias propias, al margen de las decisiones legales, siendo bien significativo que con posterioridad, el legislador ha positivado lo que ya jurisprudencialmente había creado el Tribunal Constitucional. Se corre el peligro de recurrir espuriamente a las sentencias interpretativas para realizar cambios estructurales en el sistema constitucional.

\subsection{Sentencias Evolutivas}

No puede negarse la dificultad que entraña la interpretación de normas con una considerable antigüedad, de décadas o, incluso, de siglos. La averiguación del sentido y alcance de la norma debe atenerse al espíritu y finalidad de la misma pero atendiendo a la realidad social del tiempo en que ha de ser aplicada (elemento sociológico). En el artículo 3.1 del título preliminar del Código Civil español, se dispone que las normas se interpretarán "en relación con [ ] la realidad social del tiempo en que han de ser aplicadas [ ]". Además de mencionar los elementos literal, sistemático, histórico y teleológico, este precepto hace una referencia expresa a la realidad social del tiempo de aplicación.

Es un mandato de actualización dirigido a los intérpretes del derecho que convierte el elemento evolutivo en uno más de los declarados formalmente. Es decir, la interpretación evolutiva "no es ya una opción del intérprete, afirmada por la práctica judicial, sino un mandato de actualización interpretativa impuesto por el legislador".

El realismo jurídico americano ya advertía de que la sociedad tiene un ritmo de cambio más rápido que el Derecho y que las innovaciones y cambios legislativos suelen tener como objetivo que el orden jurídico de respuesta a las necesidades cambiantes. Sin embargo, no siempre resultan sencillos los cambios legislativos porque, como ya sabemos, cuanto mayor es el rango de la norma, más rígida resulta. De ello deriva que la Constitución, como norma de rango superior, no puede cambiarse, reformarse o modificarse fácilmente. Esta rigidez que protege a las normas y, especialmente las de la Constitución, hace estático al ordenamiento constitucional que difícilmente sufre transformaciones formales (reformas). Cuanto más subamos en la jerarquía de las fuentes más dificultosa resulta la renovación a través de la reforma o la derogación.

Canosa Usera señala que "se hacen imprescindibles otras vías que eviten la esclerosis del ordenamiento jurídico". Y subraya que la vía principal para dotar al ordenamiento de cierto dinamismo es precisamente el recurrir al denominado elemento "evolutivo" "que permite a las disposiciones normativas afrontar los cambios de la vida sin sufrir modificaciones en su texto, pero manteniendo su eficacia, es decir, regulando efectivamente la realidad". 
El juez que interpreta evolutivamente el ordenamiento no es el mero instrumento que pronuncia las palabras de la ley, seres inanimados que no pueden moderar ni la fuerza ni el rigor de la ley, como apuntaba Montesquieu. Cuando el juez interpreta en clave evolutiva es porque no puede expresar la voluntas legislatoris que, a su vez, no podía prever cómo iba a evolucionar la realidad futura. Sin embargo, a la vista de esos cambios, intenta hallar en el enunciado normativo un sentido que permita a la disposición seguir siendo eficaz.

Algunos autores - como Canosa Usera y García Belaunde - son partidarios de una interpretación evolutiva pero alertan contra el peligro de la desnaturalización y quebrantamiento de la Constitución.

Un ejemplo de aplicación del criterio de la interpretación "evolutiva" del Tribunal Constitucional español ha sido el recurso de inconstitucionalidad por la ley que permite el matrimonio entre personas del mismo sexo.

Se suscita la polémica a raíz de la aprobación de la Ley 13/2005, de 1 de julio, por la que se modifica el Código Civil en materia de derecho a contraer matrimonio, permitiendo el matrimonio entre personas del mismo sexo. La llamada "ley del matrimonio homosexual" de 2005, en España, partía de agregar un párrafo al artículo 44 del Código Civil: "el matrimonio tendrá los mismos requisitos y efectos cuando ambos contrayentes sean del mismo o de diferente sexo". Se presentó un recurso de inconstitucionalidad de esta ley, planteando varias causas de inconstitucionalidad.

El concepto jurídico de matrimonio es el que ha dado lugar a argumentaciones de variado tipo. La polémica residía en que la Constitución española sólo alude al matrimonio entre hombre y mujer. Por tanto, si se quería introducir esa regulación, algunos sectores sostienen que se debería de haber realizado una reforma de la Constitución o bien, haber legislado sobre las uniones de las personas del mismo sexo, otorgándoles los mismos derechos que a un matrimonio, pero sin que se abriera el término "matrimonio" a una unión que no contempla el texto constitucional.

El Tribunal Constitucional se pronunció mediante la Sentencia del Pleno de fecha 6 de noviembre de 2012 - STC 198/2012 - dictada en el Recurso de inconstitucionalidad núm. 6864/2005147. La sentencia desestimó el recurso interpuesto contra la Ley 13/2005, de 1 de julio.

La mayoría de los magistrados - ocho frente a tres- suscriben que el reconocimiento del matrimonio entre parejas del mismo sexo no altera la institución del matrimonio, vista desde una interpretación evolutiva:

La institución matrimonial se mantiene en términos perfectamente reconocibles para la imagen que, tras una evidente evolución, tenemos en la sociedad española actual del matrimonio, como comunidad de afecto que genera un vínculo o sociedad de ayuda mutua entre dos personas que poseen idéntica posición en el seno de esta institución.

La sentencia considera que la Constitución "a través de una interpretación evolutiva se acomoda a las realidades de la vida moderna como medio para asegurar su propia relevancia y legitimidad". Aduciendo estudios de opinión, el tribunal concluye que el matrimonio entre parejas del mismo sexo goza de "una amplia aceptación social" en España, también recuerda que, desde 2005, se ha aprobado en otros países. 


\section{Humanos \\ Democracia}

\section{REFLEXIONES FINALES}

Para que el Tribunal Constitucional español cumpliera eficazmente su función garantista, el ordenamiento jurídico español debería modificarse tres aspectos sustanciales que impiden que alcance su efectividad de garante de la Carta Magna y de los derechos fundamentales:

- Recuperar la cuestión de inconstitucionalidad de manera que los jueces ordinarios puedan plantear cuestiones de inconstitucionalidad al TC (y no que sean únicamente los poderes públicos los que puedan hacerlo). ${ }^{12}$

- Imposibilidad de retirar los recursos de inconstitucionalidad interpuestos. Si se ha presentado un recurso de inconstitucionalidad - por ejemplo, por un partido político que no está en el gobierno con respecto a una ley aprobada en el Congreso - que no se pueda retirar tal recurso en un momento posterior (generalmente por un acuerdo político con el partido de la oposición). Si se ha considerado que una ley o un Decreto-Ley es inconstitucional y vulnera los preceptos constitucionales, hay que velar por la constitucionalidad de todo el ordenamiento jurídico y no limitarse a acuerdos de conveniencia.

- Implantar vis expansiva de declaración de inconstitucionalidad para leyes que sean idénticas a las recurridas. El TC en determinadas sentencias ha declarado inconstitucional algunas normas de ciertos Estatutos de Autonomía, normas que cuyo contenido sustancial se reproduce en otros Estatutos. Sin embargo, como en los otros Estatutos no se ha interpuesto recurso de inconstitucionalidad, siguen vigentes. Debería de establecerse que esa declaración de inconstitucionalidad de un precepto, que se repite en otras normativas, aunque no se haya planteado recurso, expansivamente se fueran también afectadas por la inconstitucionalidad declarada por el TC.

- No puede admitirse la contaminación iusprivatista de la justicia constitucional, porque lo que se ve afectado en muchas ocasiones es el bien público - y no exclusivamente derechos individuales.

- Conveniencia de clarificar las posibilidades del recurso de amparo por vulneración de derechos fundamentales. La exigencia de especial "trascendencia constitucional" para su admisión, concepto indeterminado, da lugar a un cierto grado de inseguridad jurídica para los recurrentes.

Por último, concluimos con unas palabras de Zagrebelsy:

Hoy, ciertamente, los jueces tienen una gran responsabilidad en la vida del derecho desconocida en los ordenamientos del Estado de derecho legislativo. Pero, los jueces no son los señores del derecho en el mismo sentido en que lo era el legislador en el pasado siglo. Son más exactamente los garantes de la complejidad estructural del derecho en el Estado constitucional, es decir, los garantes de la necesaria y dúctil coexistencia entre ley, derechos y justicia. Es más, podríamos afirmar como conclusión que entre el Estado constitucional y cualquier "señor del derecho" hay una radical incompatibilidad. El derecho no es un objeto propiedad de uno, sino que debe ser objeto del cuidado de todos" $(1995$, p. 153).

\footnotetext{
12 El Tribunal Constitucional, a través de la cuestión de inconstitucionalidad, al igual que a través del recurso de inconstitucionalidad, garantiza la supremacía de la Constitución y enjuicia la conformidad o disconformidad con ella de las leyes, disposiciones normativas y actos con fuerza de ley del Estado y de las Comunidades Autónomas. La cuestión de inconstitucionalidad sólo puede ser promovida, de oficio o a instancia de parte, por Jueces y Tribunales y han de hacerlo cuando consideren que una norma con rango de ley aplicable al proceso del que conocen y de cuya validez dependa la decisión que hayan de adoptar en el mismo pueda ser contraria a la Constitución.
} 


\section{REFERENCIAS}

ARAGÓN REYES, M. Las dimensiones subjetiva y objetiva del nuevo recurso de amparo. Otrosí, n. 10, 2012. BECK, U. La Europa cosmopolita. Claves de razón práctica, n. 155, 2005, p. 18-25.

BELLOSO MARTíN, N. De nuevo sobre la interpretación de los derechos fundamentales: reflexiones a la luz de algunas sentencias. In: BELLOSO MARTíN, Nuria; RODRIGUES, Saulo Tarso; LOBATO, Anderson (ed.). A contribuição da justiça constitucional para a cidadania. Reflexões de Direito Comparado. Rio Grande: Editora da Universidade Federal de Rio Grande - Furg, 2015. p. 75-156.

BELLOSO MARTÍN, N. La Jurisdicción constitucional en las democracias constitucionales: su discutida configuración como poder contramayoritario y cómo órgano con auténtico poder normativo. In: DE JULIOS CAMPUZANO, Alfonso (ed.). Itinerarios constitucionales para un mundo convulso. Madrid: Dykinson, 2017. p. 31-65.

FERNÁNDEZ SEGADO, F. El Tribunal Constitucional español como legislador positivo. Pensamiento Constitucional, año XV, n. 15, p. 127-192, 2011. Disponible en: revistas.pucp.edu.pe/index.php/.../article/download/.../2910.

FERRAJOLI, L. Derecho y Razón. Teoría del garantismo penal. 10. ed. Madrid: Trotta, 2016a.

FERRAJOLI, L. Principia Juris. Teoría del derecho y de la democracia. 2. ed. Madrid: Trotta, $2016 \mathrm{~b}$.

JIMENO BULNES, M. Un proceso europeo para el siglo XXI. Lección inaugural del curso académico 2018-2019. Burgos: Rico Adrados S. L., 2018.

NUNEZ LEIVA, J. I. Garantismo espurio. lus et Praxis, Talca, v. 16, n. 2, p. 495-498, 2010. Disponible en: https:// scielo.conicyt.cl/scielo.php?script=sci_arttext\&pid=S0718-00122010000200019\&lng=es\&nrm=iso. Acceso en: 9 sept. 2018. DOI: http://dx.doi.org/10.4067/S0718-00122010000200019.

OLLERO TASSARA, A. Legalidad y constitucionalidad. Anuario de Filosofía del Derecho, v. XXXIV, p. 95-118, 2018. ZAGREBELSKY, G. El derecho dúctil. Ley, derechos, justicia. Madrid: Trotta, 1995.

\section{JURISPRUDENCIA}

https://tc.vlex.es/

STC del pleno 177/2015, de 22 de julio. Libertad de expresión vs. injurias al Rey. Boletín Oficial del Estado. Disponible en: https://www.boe.es. Acceso en: 21 ago. 2015.

STC 214/1991, de 11 de noviembre. "Caso Violeta Friedman". Disponible en: http://hj.tribunalconstitucional.es/ cs/Resolucion/Show/1853.

STC 154/2002, de 18 de julio. "Caso testigos de Jehová". Disponible en: http://hj.tribunalconstitucional.es/es/ Resolucion/Show/4690.

STC Pleno. Sentencia 31/2010, de 28 de junio de 2010. Estatuto de Cataluña. Boletín Oficial del Estado. Disponible en: https://boe.es. Acceso en: 16 jul. 2010.

STC 43/2009, de 12 de febrero. Sentencia Bildu. Boletín Oficial del Estado. Disponible en: https://www.boe.es. Acceso en: 20 jun. 2009.

Sentencia del Pleno de fecha 6 de noviembre de 2012 - STC 198/2012 - Matrimonio entre personas del mismo sexo. Disponible en: https://www.boe.es.

STJUE (Sala Tercera), de 8 de mayo de 2019. Disponible en: http://curia.europa.eu/juris/document/document. jsf?text=\&docid=213852\&pagelndex=0\&doclang=ES\&mode=Ist\&dir=\&occ=first\&part=1\&cid=7555428.

STJUE (Gran Sala) de 21 de diciembre de 2016. Disponible en: https://ep00.epimg.net/.../26aea35b8c66e78f3169264b9f90ecbe...

TRIBUNAL de JUSTICIA de la UNIÓN EUROPEA. Disponible en: https://curia.europa.eu/jcms/jcms/j_6/es/. DEFENSOR del PUEBLO EUROPEO. Disponible en: https://www.ombudsman.europa.eu/es/home.

JURISPRUDENCIA del TEDH. Disponible en: https://www.mjusticia.gob.es/cs/Satellite/Portal/es/areas-tematicas/area-internacional/tribunal-europeo-derechos/jurisprudencia-tedh/articulo-derecho-vida\#Se_1288807922455_1.

MANUALES, fichas y vídeos temáticos sobre los derechos humanos protegidos. Disponible en: https://www. mjusticia.gob.es/cs/Satellite/Portal/es/areas-tematicas/area-internacional/tribunal-europeo-derechos/manuales-fichas-tematicas. 